\title{
Bcl-2 associated athanogene 4 promotes proliferation, migration and invasion of gastric cancer cells
}

\author{
LIZHI YI $^{1 *},{\text { ZHENBING } \text { LV }^{2,3 *}, \text { JIANMEI WANG }^{4} \text { and XIANFEI ZHONG }}^{1}$ \\ ${ }^{1}$ Department of Gastroenterology, Leshan People's Hospital, Leshan, Sichuan 614000; ${ }^{2}$ Department of General Surgery Two, \\ Nanchong Central Hospital; ${ }^{3}$ The Second Clinical School of North Sichuan Medical College, Nanchong, Sichuan 637000; \\ ${ }^{4}$ Department of Pathology, The Affiliated Hospital of Southwest Medical University, Luzhou, Sichuan 646000, P.R. China
}

Received May 22, 2016; Accepted April 4, 2017

DOI: $10.3892 / \mathrm{mmr} .2017 .7073$

\begin{abstract}
Currently, with the increase of morbidity and mortality rate, gastric cancer (GC) is attracting increasing attention in China. Bcl-2-associated athanogene 4 (BAG4) has been identified as a tumor promoter in several tumors, but its role in GC remains unknown. The present study aimed to detect the expression of BAG4 and determine its function in the progression of GC. The results from reverse transcription-quantitative polymerase chain reaction and western blotting revealed that BAG4 was markedly upregulated in highly metastatic cell lines (SGC7901 and MGC803), compared with the lower-metastatic cell lines (AGS and BGC823). Through Cell Counting Kit-8, cell cycle, apoptosis, Transwell and colony formation assays, BAG4 was demonstrated to promote the proliferation, migration and invasion of GC cells in vitro. Additionally, in vivo assays further certified that BAG4 can increase the proliferation and invasion of GC cells. In conclusion, these findings implicate BAG4 as a potential therapeutic target for GC.
\end{abstract}

\section{Introduction}

Currently, gastric cancer (GC) is the fourth most common malignancy in the world (1). The development of GC is a multistep process, involving progressive disruption of epithelial-cell proliferation, apoptosis, differentiation and survival mechanisms $(2,3)$. With advancing modern medical therapies,

Correspondence to: Miss Jianmei Wang, Department of Pathology, The Affiliated Hospital of Southwest Medical University, 25 Taiping Street, Luzhou, Sichuan 646000, P.R. China

E-mail: 971171080@qq.com

Mr. Xianfei Zhong, Department of Gastroenterology, Leshan People's Hospital, 238 Baita Street, Leshan, Sichuan 614000, P.R. China

E-mail: 651218437@qq.com

*Contributed equally

Key words: Bcl-2 associated athanogene 4, proliferation, migration, invasion, gastric cancer the rate of GC mortality has been decreased (4). It is necessary to identify the biomarkers that can distinguish between $\mathrm{GC}$ patients with poor or good prognosis.

Bcl-2 associated athanogene 4 [BAG4, also known as Silencer of Death Domains (SODD)] is a member of the BAG1-related protein family (5). The BAG proteins are located in both cytoplasmic and nuclear in cells (6), although the functional importance of this remains unclear. BAG proteins have a conserved BAG domain (BD) that binds to the ATPase domain of Hsp70/Hsc70, and regulates the activity of these molecular chaperones (7-9). Previous studies have reported that BAG protein family members are associated with aggressiveness of breast, gastric, and pancreatic cancer (10-13). Furthermore, loss of BAG4 is associated with the resistance of platinum chemotherapy $(6,14)$. However, the role of BAG4 in gastric cancer remains unclear.

The present study detected the expression of BAG4 in GC cell lines and examined the effect of BAG4 on GC cell proliferation, migration and invasion in vitro and in vivo.

\section{Materials and methods}

Cell lines and animals. The SGC7901, BGC823, AGS, MGC803 and MKN45 human GC cell lines were purchased from the Chinese Academy of Sciences (Beijing, China) and cultured in RPMI-1640 medium (Thermo Fisher Scientific, Inc., Waltham, MA, USA) with $10 \%$ fetal bovine serum (Thermo Fisher Scientific, Inc.). All cell lines were cultured in $5 \% \mathrm{CO}_{2}$ at $37^{\circ} \mathrm{C}$. A total of 24 male athymic BALB/c mice (age, 4-6 weeks old, 15.2-16.3 g) were purchased from the Central Laboratory of Animal Science at North Sichuan Medical College (Nanchong, China). They were housed at $24^{\circ} \mathrm{C}$, with a humidity of $60-70 \%$, a 12 -h light/dark cycle and free access to food and water All protocols for animal studies were reviewed and approved by the Institutional Animal Care and Use Committee of North Sichuan Medical College in accordance with the NIH Guide for the Care and Use of Laboratory Animals (15) and the Animal Welfare Act.

Construction of plasmids and transfection. For overexpression or depletion of BAG4, AGS cell lines were selected for stable transfection with a BAG4-expressing vector, and SGC7901 cell lines were selected for transient transfection with short hairpin 
(sh)RNA lentivirus vectors (Shanghai GeneChem Co., Ltd., Shanghai, China) for BAG4. The lentivirus vectors carrying the fragment of coding sequence (CDS) or short hairpin (sh)RNA were transfected into 293T lentiviral packaging cell lines. The primers were as follows: Forward, 5'-ATGTCG GCCCTGAGGCGCT-3' and reverse, 5'-TCATAATCCTTT TTTTTCTAATTTT-3' for BAG4; and 5'-CCAACAATCAAG ATCAAAGTA-3' for shRNA. Following this, $1 \mathrm{ml}$ viral supernatant containing $4 \mu \mathrm{g}$ polybrene was added into GC cell lines for stable transduction. After 14 days, puromycin-resistant cell pools were established. After $72 \mathrm{~h}$, the protein expression level of BAG4 was detected by western blot analysis, and transfected cells were subjected to Transwell assay.

Transwell assay. The invasion Boyden Chambers (BD Biosciences, Franklin Lakes, NJ, USA) were rehydrated with RPMI-1640 (serum-free) for $2 \mathrm{~h}$ at $37^{\circ} \mathrm{C}$. RPMI 1640 supplemented with $100 \mathrm{ml} / \mathrm{l}$ fetal bovine serum was added to the lower compartment as the chemotactic factor. Following this, $1.5 \times 10^{5}$ tumor cells in serum-free RPMI 1640 were added to the upper compartment of the chamber. Each cell group was plated into three duplicate wells. After incubation for $48 \mathrm{~h}$, the noninvasive cells were removed with a cotton swab. Cells that had migrated through the membrane and stuck to the lower surface of the membrane were fixed with methanol and stained with hematoxylin. Finally, the cells in lower compartment of the chamber that had migrated to the lower sides of the membrane were counted under a light microscope in five random visual fields (magnification, x200).

RNA extraction and reverse transcription-quantitative polymerase chain reaction ( $R T-q P C R)$. RNA was extracted from the five cell lines using TRIzol reagent (Invitrogen; Thermo Fisher Scientific, Inc., Waltham, MA, USA) and cDNA was synthesized using an access reverse transcription system (Promega Corporation, Madison, WI, USA). The temp/duration of the RT reaction was as follows: $37^{\circ} \mathrm{C}$ for $15 \mathrm{~min}$ and $85^{\circ} \mathrm{C}$ for $5 \mathrm{sec}$. qPCR was performed using 7500 Fast Real-time PCR System (Thermo Fisher Scientific, Inc.), using the following thermal cycling profile: $95^{\circ} \mathrm{C}$ for $10 \mathrm{~min}$, followed by 35 cycles of amplification $\left(95^{\circ} \mathrm{C}\right.$ for $10 \mathrm{sec}, 60^{\circ} \mathrm{C}$ for $30 \mathrm{sec}$ and $72^{\circ} \mathrm{C}$ for $\left.34 \mathrm{sec}\right)$. The method of quantification was adapted from Livak and Schmittgen (16). The PCR primers were as follows: forward, 5'-AATGGAGCGTATGGT CCAACA-3' and reverse, 5'-GGTGCATAATAAGCCCCT GAGT-3' for BAG4; and 5'-AGGTCGGTGTGAACGGAT TTG-3' and reverse, 5'-GGGGTCGTTGATGGCAACA-3' for GAPDH. First-strand cDNA was synthesized using a SYBR PrimeScript RT Reagent kit (Takara Biotechnology Co., Ltd., Dalian, China). qPCR was performed using SYBR Premix Ex Taq II (Takara Biotechnology Co., Ltd.) and measured in a LightCycler 480 system (Roche, Basel, Switzerland). Human GAPDH gene was amplified as an internal control. Each sample was tested three times and all other quantities were expressed as an $\mathrm{n}$-fold difference relative to the corresponding control group.

Cell proliferation assay. AGS and SGC7901 cells $\left(1 \times 10^{3}\right)$ were seeded into 96-well plates. The number of viable cells was determined by Cell Counting Kit-8 (CCK-8; Dojindo
Molecular Technologies, Inc., Kumamoto, Japan) for 6 days. Briefly, $10 \mathrm{ml} \mathrm{CCK}-8$ solution was added, and absorbance was measured at a wavelength of $490 \mathrm{~nm}$ using a microplate reader (Enspire 2300 M R; PerkinElmer, Inc., Waltham, MA, USA) after $2 \mathrm{~h}$ of incubation at $37^{\circ} \mathrm{C}$. Each cell group was plated into three duplicate wells.

Cell cycle analysis. AGS and SGC7901 cells $\left(\sim 1 \times 10^{6}\right)$ cells were trypsinized, washed twice with PBS and fixed in 70\% ice-cold ethanol for $1 \mathrm{~h}$. The samples were centrifuged at $300 \mathrm{x} \mathrm{g}$ for $5 \mathrm{~min}$ at $4^{\circ} \mathrm{C}$, the ethanol removed and they were exposed to $100 \mathrm{mg} / \mathrm{ml}$ RNaseA (Sigma-Aldrich; Merck $\mathrm{KGaA}$, Darmstadt, Germany) for $30 \mathrm{~min}$ at $37^{\circ} \mathrm{C}$. Cellular DNA was stained with propidium iodide (Nanjing KeyGen Biotech Co., Ltd., Nanjing, China). Cell-cycle distributions were determined by flow cytometry using a BD FACSCalibur system (BD Biosciences, Franklin Lakes, NJ, USA) and data was analyzed using the ModFit software version 4.1 (Verity Software House, Inc., Topsham, ME, USA).

In vitro apoptosis assay. AGS and SGC7901 cells were transfected with $50 \mathrm{nM}$ oligo using Lipofectamine ${ }^{\circledR} 2000$ according to the manufacturer's protocol (Invitrogen; Thermo Fisher Scientific, Inc., Waltham, MA, USA). Cells were subsequently harvested and stained with Annexin V-fluorescein isothiocyanate (FITC) and propidium iodide (PI), according to the manufacturer's protocol (BioVision, Inc., Milpitas, CA, USA). Annexin V-FITC/PI binding was analyzed by flow cytometry using a BD FACSCalibur system and data was analyzed using the CellQuest software version 5.1 (BD Biosciences, Franklin Lakes, NJ, USA).

In vivo tumorigenesis assay. To evaluate in vivo tumor growth, experimental mice were injected subcutaneously in to the left flank with $1 \times 10^{7}$ AGS cells carrying BAG4 overexpressing vector and the control mice were treated with $1 \times 10^{7}$ AGS cells carrying control lentivirus vectors ( $\mathrm{n}=6$ per group). The sizes of tumors were measured with calipers to estimate volumes by length $\mathrm{x}$ width $\mathrm{x}$ height from days 5 to 35 following injection. BAG4 expression was detected in xenograft tumors by western blotting. The proliferative index of Ki-67 was evaluated in xenograft tumors by immunohistochemistry (IHC). For tail vein metastasis assay, a total of $1 \times 10^{6}$ cells were injected into the tail veins of nude mice. After 35 days, the mice were sacrificed and the lung tissues dissected out and subjected to histological examination. Metastatic tumors were detected by $\mathrm{H} \& \mathrm{E}$ staining and quantified by counting metastatic lesions in each section. Images were captured by Olympus DP72 microscope and were analyzed by DP2-BSW software version 1.3 (Olympus Corporation, Tokyo, Japan).

$I H C$. After dissection, tissues were washed twice with PBS and fixed with $10 \%$ neutral formalin for $2 \mathrm{~h}$ and embedded in paraffin. Then paraffin-embedded specimens were cut into $4 \mathrm{~mm}$ sections. The sections were deparaffinized with xylene and rehydrated. Sections were submerged into EDTA antigenic retrieval buffer and microwaved for $10 \mathrm{~min}$ for antigenic retrieval. The sections were treated with $3 \%$ hydrogen peroxide in methanol to quench the endogenous peroxidase activity. Rabbit monoclonal antibody against Ki67 (ab92742; 
A

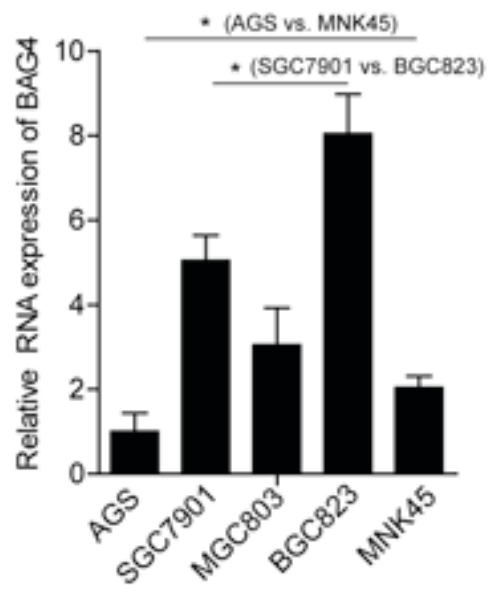

C

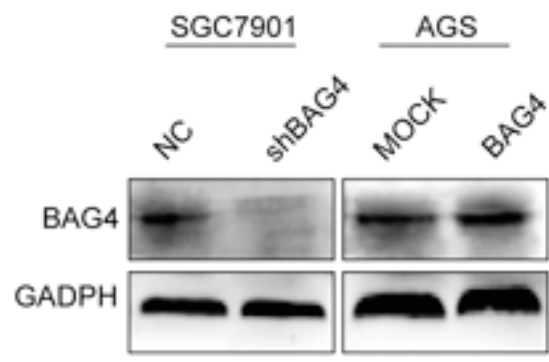

B
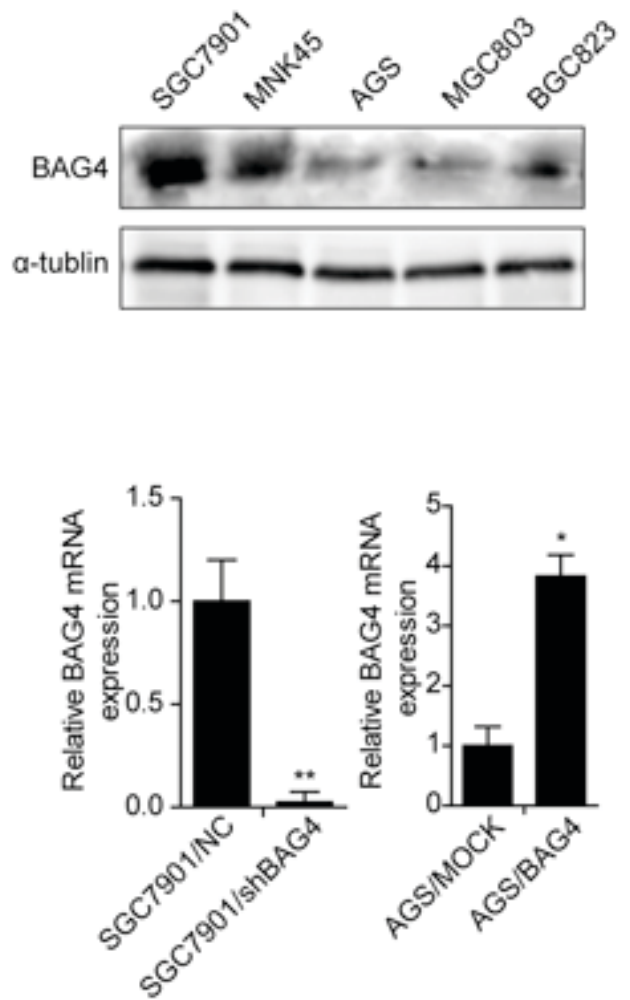

Figure 1. BAG4 is upregulated in human gastric cancer cell lines. (A) mRNA and (B) protein expression levels of BAG4 in the five GC cell lines, as assessed by RT-qPCR and western blot analysis, respectively. ${ }^{*} \mathrm{P}<0.05$ BGC823 vs. AGS; ${ }^{*} \mathrm{P}<0.05$ AGS vs. MNK45. (C) Protein and mRNA expression levels of BAG4 in BAG4-knockdown AGS and BAG4-overexpressing SGC7901 cells. $\alpha$-tubulin and GAPDH served as internal controls. Data are presented as the mean \pm standard deviation of three independent experiments. ${ }^{*} \mathrm{P}<0.05 ;{ }^{* *} \mathrm{P}<0.01$. BAG4, Bcl-2, associated athanogene 4; RT-qPCR, reverse transcription-quantitative polymerase chain reaction.

1:1,000; Abcam, Cambridge, UK) were incubated with the sections overnight at $4^{\circ} \mathrm{C}$. After incubation with $50 \mu \mathrm{l}$ per section goat anti-rabbit IgG/horseradish peroxidase (HRP) polymer secondary antibody for $30 \mathrm{~min}$ (PV-6001; ZSGB-Bio Co., Ltd., Beijing, China), the visualization signal was developed with 3,3'-diaminobenzidine tetrachloride (ZSGB-Bio Co., Ltd.) for $3 \mathrm{~min}$. Images were captured by Olympus DP72 microscope (Olympus Corporation) and were analyzed with DP2-BSW software. The stained tissue sections were reviewed and scored separately by two pathologists blinded to the clinical parameters. The total Ki67 immunostaining score was calculated as the sum of the percent positivity of stained tumor cells.

Western blotting. Cells were collected and washed twice with PBS and then lysed with lysis buffer (Nanjing KeyGen Biotech Co., Ltd.) for $30 \mathrm{~min}$ on ice. Xenograft tissues were ground up in liquid nitrogen and lysed with 100-200 $\mu \mathrm{l}$ lysis buffer (Nanjing KeyGen Biotech Co., Ltd.) for $30 \mathrm{~min}$ on ice. The proteins were then centrifuged at $11,000 \mathrm{x} \mathrm{g}$ for $20 \mathrm{~min}$ at $4^{\circ} \mathrm{C}$. The concentrations of proteins were detected by BCA kit (Bioworld, Guangzhou, China). Then, $30 \mu \mathrm{g}$ protein was separated by $10 \%$ SDS-PAGE and transferred onto polyvinylidene difluoride membranes. Membranes were blocked with 5\% BSA for $1 \mathrm{~h}$ and incubated with rabbit polyclonal anti-BAG4 (ab2048; 1:100; Abcam), mouse monoclonal anti- $\alpha$-tubulin (T6199; 1:1,000; Sigma-Aldrich; Merck KGaA) and anti-GAPDH (G8795; 1:1,000; Sigma-Aldrich; Merck $\mathrm{KGaA}$ ) primary antibodies for overnight at $4^{\circ} \mathrm{C}$. The membranes were washed three times for 10 min with PBST (PBS 1,000:Tween-1) and incubated with HRP-conjugated goat anti-rabbit (FDR007; 1:10,000; Fdbio Science, Hangzhou, China) or anti-mouse (FDM007; 1:10,000; Fdbio Science) for $1 \mathrm{~h}$ at $37^{\circ} \mathrm{C}$. The membranes were then washed three times for 10 min with PBST and visualized with Pico ECL (Fdbio Science) by tanon-5200 (Tanon Science and Technology Co., Ltd., Shanghai, China). $\alpha$-tubulin and GAPDH served as internal controls.

Statistical analysis. Cell proliferation, in vitro and in vivo invasion assays were tested using one-way analysis of variance followed by LSD (equal variances assumed) or Dunnett's T3 (equal variances not assumed). Data were analyzed using SPSS software version 13.0 (SPSS, Inc., Chicago, IL, USA) and are presented as the mean \pm standard deviation. $\mathrm{P}<0.05$ was considered to indicate a statistically significant difference. 
A

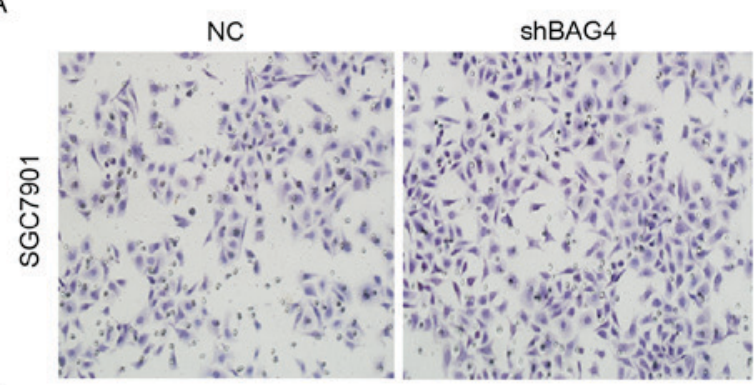

B

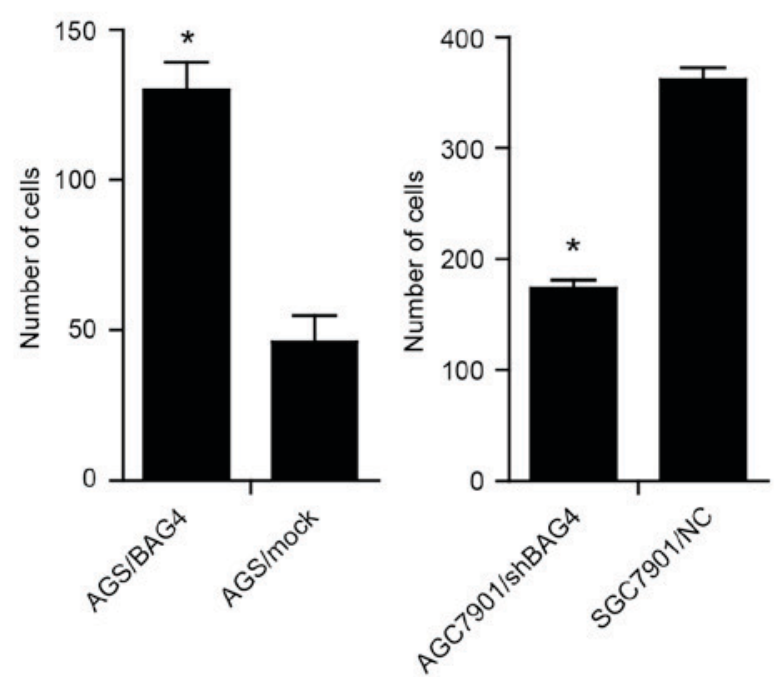

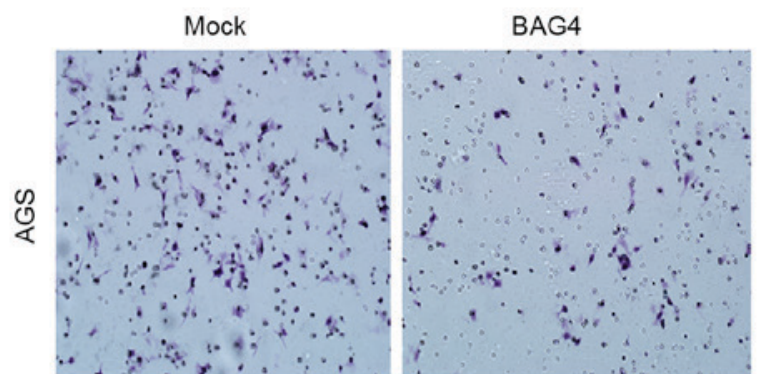

C
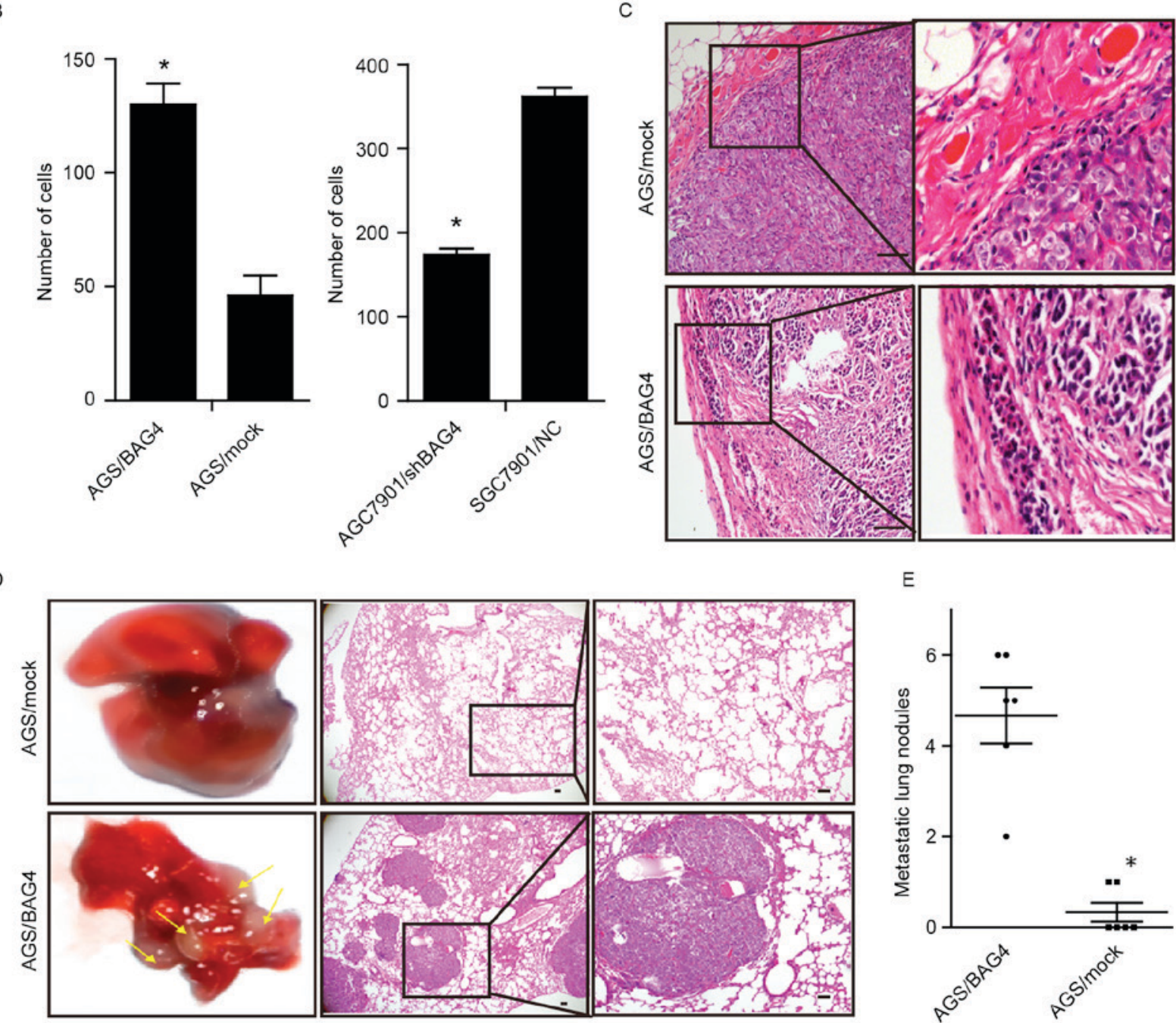

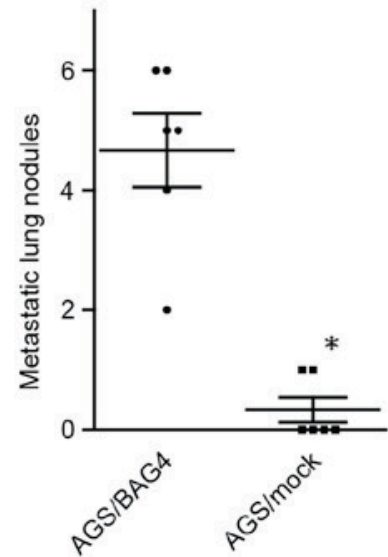

Figure 2. Effect of BAG4 on the migration and invasion of AGS and SGC790 gastric cancer cells in vitro and in vivo. (A) Effect of BAG4 knockdown or ectopic on cell invasion in vitro. Morphological comparison of cells penetrating the artificial basement membrane is presented. Magnification, $\mathrm{x} 200$. (B) Quantification of invasive cells. (C) Effect of BAG4 overexpression on cell invasion in vivo. The tumor sections were stained with H\&E. Scale bar, $20 \mu \mathrm{m}$. (D) Representative immunohistochemistry images and (E) quantification of BAG4 overexpression on pulmonary metastases in vivo. The tumor sections were stained with H\&E. Scale bar, $50 \mu \mathrm{m}$. The number of metastatic nodules in individual mice were counted under a microscope. Data are presented as the mean \pm standard deviation. ${ }^{*} \mathrm{P}<0.05$. H\&E, hematoxylin and eosin; BAG4, Bcl-2, associated athanogene 4; sh, short hairpin; NC, negative control.

\section{Results}

BAG4 is upregulated in human GC cell lines. First, the expression of BAG4 in five human GC cell lines were assessed by RT-qPCR and western blotting. The mRNA (Fig. 1A) and protein (Fig. 1B) expression levels of BAG4 were increased in more aggressive GC cell lines (SGC7901 and MGC803) and lower in less aggressive GC cell lines (AGS and BGC823). Therefore, it was hypothesized that BAG4 may be associated with invasion and metastasis of GC.
Effect of BAG4 on migration and invasion of $G C$ cells in vitro. To investigate the role of BAG4 in the progression of $\mathrm{GC}$, loss and gain of function were performed examine the effect of BAG4 on cell migration and invasion in vitro and in vivo. AGS cell lines were selected for stable transfection with a BAG4-expressing vector, and SGC7901 cell lines were selected for transient transfection with shRNA lentivirus vectors for BAG4. Transfection efficiency was validated by RT-qPCR and western blot analysis. The results demonstrated that shRNA successfully knocked down BAG4 protein 
A

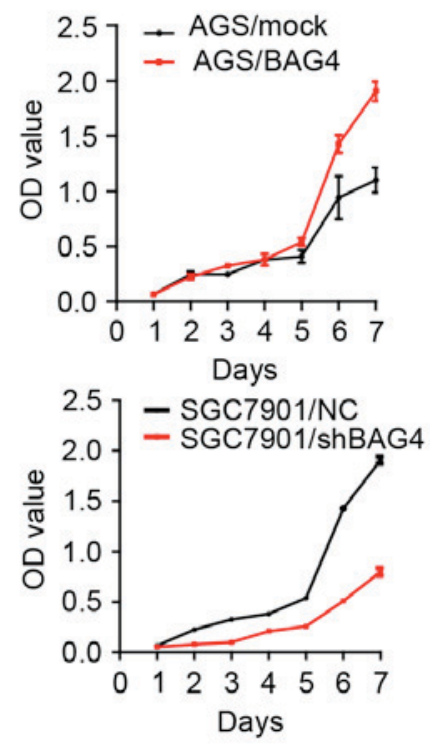

B
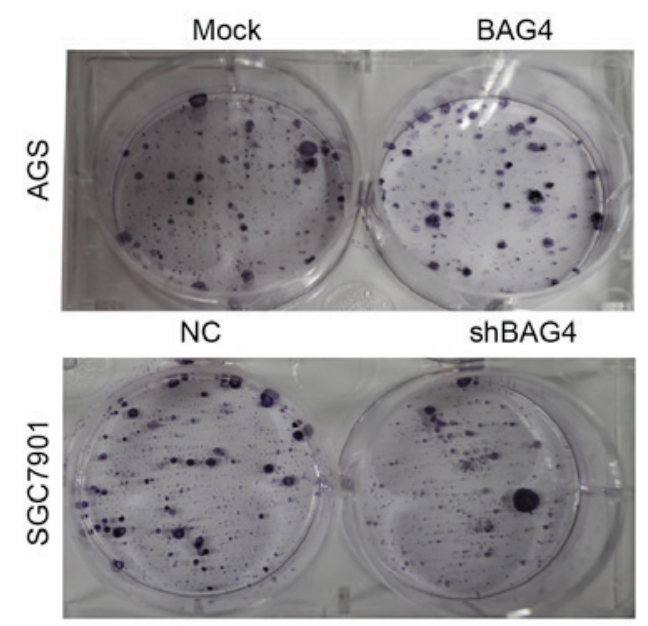

C

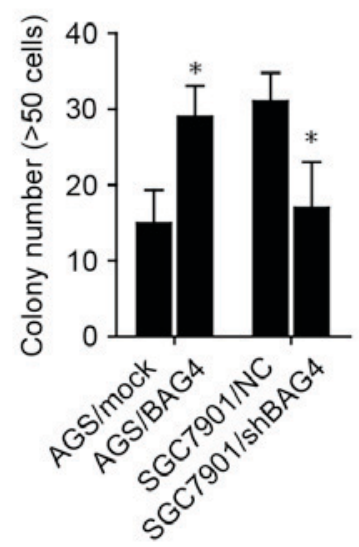

Figure 3. Effect of BAG4 on the proliferation of GC cells in vitro and in vivo. (A) Effect of BAG4 knockdown or overexpression on cell proliferation in vitro, as assessed by Cell Counting Kit-8 assay. (B) Effect of BAG4 knockdown or overexpression on cell proliferation in vitro by colony formation assay. (C) Quantification of colony numbers (cells $>50$ ). Data are presented as the mean \pm standard deviation. ${ }^{*} \mathrm{P}<0.05$ AGS/mock vs. AGS/BAG4 and SGC7901/NC vs. SGC790/shBAG4. BAG4, Bcl-2, associated athanogene 4; sh, short hairpin; NC, negative control; OD, optical density.

(Fig. 1C) and mRNA (Fig. 1D) expression levels. Furthermore, BAG4 was successfully overexpressed in AGS cells, compared with mock cells (Fig. 1C and D).

The results of the Boyden Chamber assay demonstrated that BAG4-depleted SGC7901 cells exhibited a marked decrease of invasive ability, whereas overexpression of BAG4 demonstrated the opposite effect (Fig. 2A and B; both $\mathrm{P}<0.05$ ). Furthermore, BAG4-expressing subcutaneous tumors exhibited evidence of local invasion, whereas control tumors were well encapsulated and noninvasive (Fig. 2C). To test the effect of BAG4 on GC metastasis in vivo, BAG4-overexpressing AGS cells were injected into the tail vein of nude mice to examine the role of BAG4 in lung colonization. BAG4 markedly promoted lung tumor metastases (Fig. 2D). In AGS cells, the numbers of metastatic lesions in the BAG4-expressing group was significantly increased compared with the control group $(\mathrm{P}<0.05$; Fig. 2E). The results indicated that BAG4 suppresses migration and invasion of GC cells.

Effect of BAG4 on the proliferation of GC cells in vitro and in vivo. The role of BAG4 on proliferation of GC cells was investigated. The results of the CCK- 8 assay demonstrated that overexpression of BAG4 caused a significant increase of the proliferation rate in the AGS cell line, whereas BAG4 depletion decreased the proliferation of SGC7901 cell $(\mathrm{P}<0.05$; Fig. 3A). Similar results were observed in colony formation assays $(\mathrm{P}<0.05$, Fig. $3 \mathrm{~B}$ and $\mathrm{C})$. Furthermore, AGS cells overexpressing BAG4 exhibited a significant increase in the percentage of cells in the G1/G0 peak, and a decrease in the percentage of cells in the $\mathrm{S}$ and $\mathrm{G} 2 / \mathrm{M}$ peak $(\mathrm{P}<0.05$, Fig. 4A). However, SGC7901 cells treated with BAG4 shRNA demonstrated the opposite effect (Fig. 4B). These results suggested that BAG4 promotes GC cell proliferation by eliciting G1/G0 phase arrest. Compared with control cells, AGS cells overexpressing BAG4 showed decreased rate of apoptosis $(\mathrm{P}<0.05$; Fig. 4C), while the rate of apoptosis was remarkably increased when BAG4 was depleted in SGC7901 cells ( $\mathrm{P}<0.05$; Fig. 4D). Additionally, BAG4-overexpressing or control cells were injected subcutaneously into nude mice, and the growth of the resultant primary tumors were measured. Tumors in mice injected with BAG4-overexpressing cells grew more rapidly compared with those injected with control cells (Fig. 5A and B). IHC staining confirmed that the tumors of BAG4-overexpressing group exhibited much higher Ki67 index compared with the control group (Fig. 5C and D). These results demonstrated that BAG4 promotes $\mathrm{GC}$ cell proliferation by upregulating cell cycle progression or decreasing apoptosis.

\section{Discussion}

Although the survival rate of GC has increased recently due to modern medical treatment, the mortality rate of GC remains high (17). Molecular therapy in recent years has become increasingly important for GC patients; the identification of biomarkers in in GC etiology, progression and clinical behavior can lead to novel approaches in molecular therapy. The BAG4 protein family includes BAG1, $-2,-3,-4,-5$ and -6 (18). They share a conserved protein interaction module near the C-terminal end called the BD. The BD can bind to the ATPase domain of Hsp70/Hsc70 and regulate activity of these molecular chaperones $(19,20)$. As an inhibitor the death domain of the tumor necrosis factor receptor 1 (TNF-R1), BAG4 is also called Silencer of Death Domain (SODD). It prevents trimerization of the receptor subunits in the absence of specific signaling by binding with TNF- $\alpha(21,22)$. Subsequently, activated TNF receptors trigger apoptosis or nuclear factor $(\mathrm{NF})-\kappa \mathrm{B}$ activation. Numerous studies have reported that BAG4, as a member of BAG1-related protein family (5), can promote the development of breast, gastric and pancreatic cancer (10-13), and its upregulation may be associated with 
A

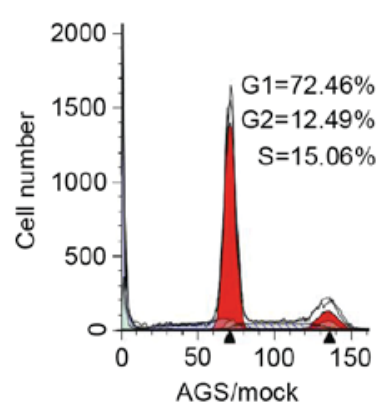

B

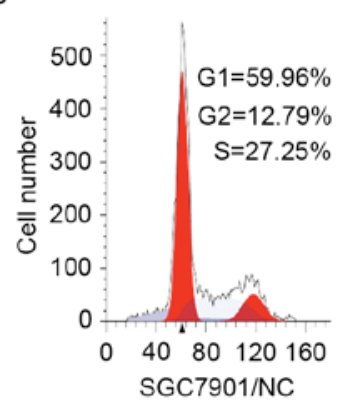

C
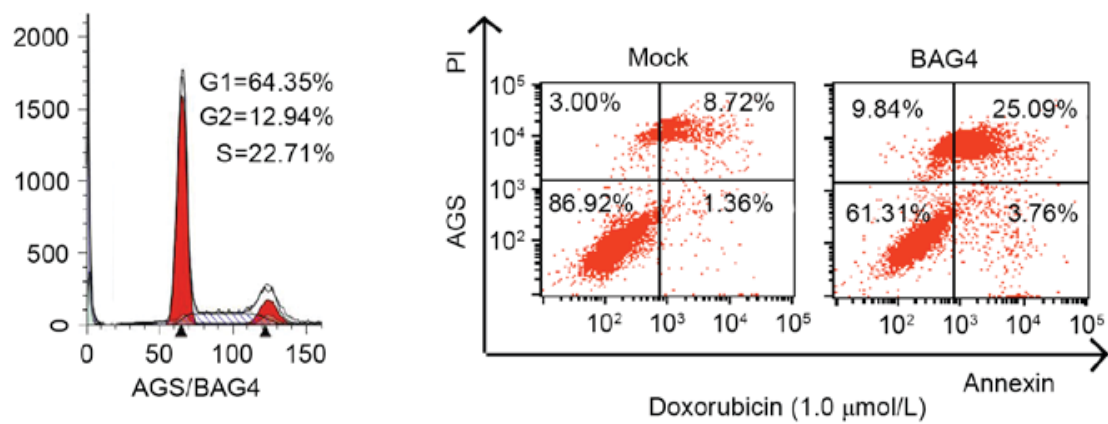

D

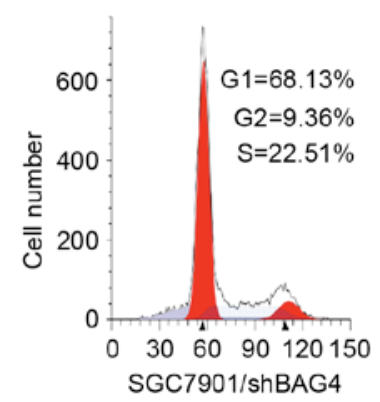

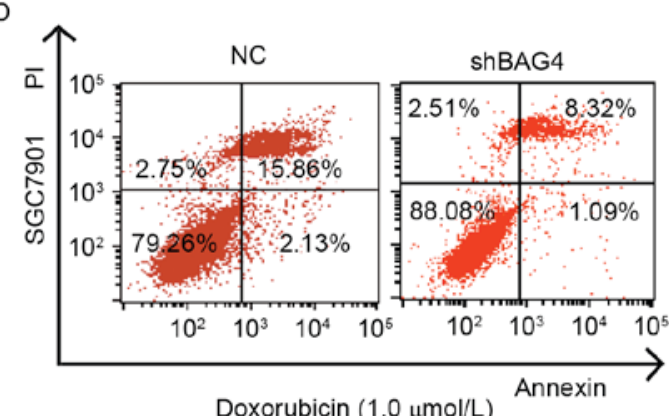

Doxorubicin $(1.0 \mu \mathrm{mol} / \mathrm{L})$

Figure 4. Effect of BAG4 on the cell cycle and apoptosis of GC cells. Representative histograms depicting cell cycle profiles of (A) BAG4-knockdown SGC7901 and (B) BAG4-overexpressing AGS cells. The percentage of apoptotic (C) SGC7901 and (D) AGS cells. BAG4, Bcl-2, associated athanogene 4; sh, short hairpin; NC, negative control; PI, propidium iodide.

A

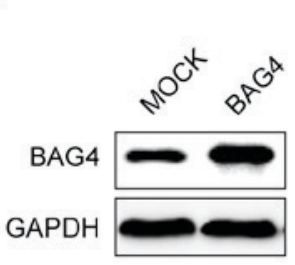

B

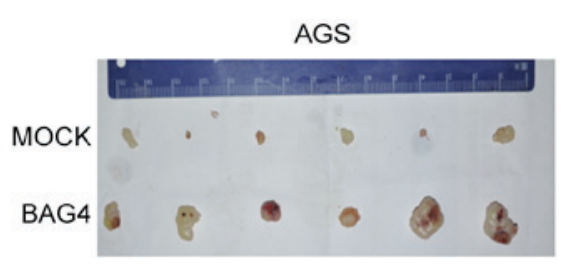

C

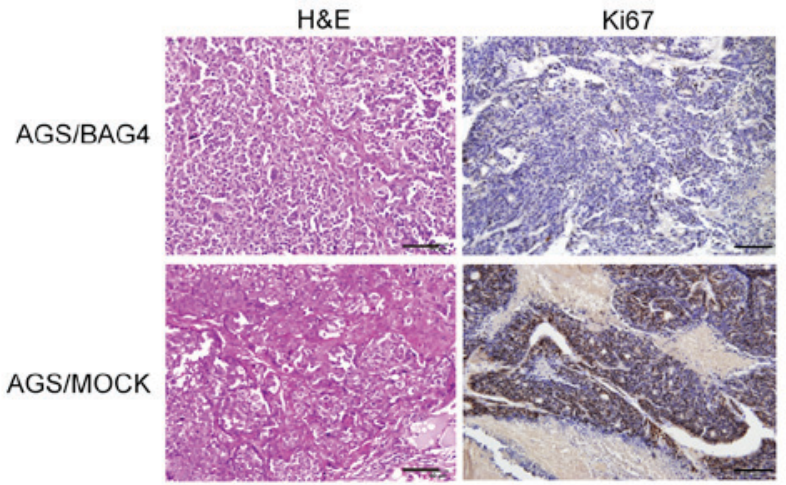

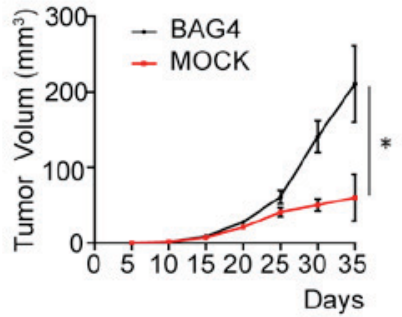

D

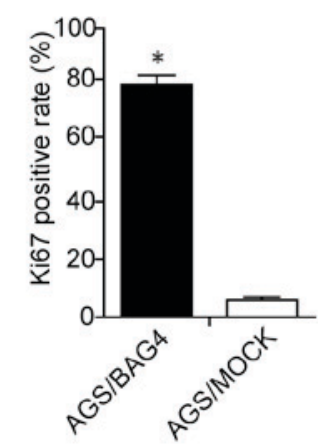

Figure 5. Effect of BAG4 on the proliferation of GC cells in vivo. (A) Protein expression levels of BAG4 in xenograft tissues, as assessed by western blot analysis. (B) Images and quantification of subcutaneous tumor sizes of mice injected with stable AGS/MOCK and AGS/BAG4 cells. AGS/MOCK group on day 35 vs. and AGS/BAG4 group on day $35^{*} \mathrm{P}<0.05$. (C) The tumor sections were stained with hematoxylin and eosin or subjected to immunohistochemistry staining using an antibody against Ki-67. Scale bar, $20 \mu \mathrm{m}$. (D) Quantification of Ki-67-positive staining. Data are presented as the mean \pm standard deviation from three independent experiments. ${ }^{*} \mathrm{P}<0.05$. BAG4, Bcl-2, associated athanogene 4; H\&E, hematoxylin and eosin.

the early recurrence of esophageal squamous cell carcinoma after definitive chemoradiation (23), and the severity of acute lymphoblastic leukemia in children (24).

The present study investigated the function of BAG4 in GC cells. Firstly, the expression levels of BAG4 in five gastric cancer cell lines were examined by western blotting and RT-qPCR. BAG4 was demonstrated to be highly expressed in SGC7901 and MNK45 cells with higher metastatic potential, and less expressed in AGS and MGC 803 cells with lower metastasic potential. Based on these data, it was hypothesized 
that BGA4 may be associated with the invasion and metastasis of GC cells. The Transwell assays indicated that downregulating BAG4 can decrease the invasiveness of SGC7901 cells, and overexpressing BAG4 served the opposite effect in AGS cells. Furthermore, subcutaneous tumor experiments demonstrated that BAG4 overexpression promotes local tumor cell invasion. The vein injection experiments demonstrated that cells overexpressing BAG4 can seed more lung localization. All these results demonstrated that $\mathrm{BAG} 4$ can promote invasion and localization of GC cells. Previous studies have indicated that BAG1 serves as an anti-apoptotic protein and interacts with other proteins to affect cell apoptosis and growth $(14,17)$. BAG1 proteins can interact with B-cell lymphoma 2 Bcl-2 to enhance resistance to apoptosis (25-27). Interestingly, BAG1 also binds to Hsp70, and inhibits the chaperone activity of this molecule $(7,8,28)$, and the downregulation of SODD and NF- $\kappa \mathrm{B}$ induces apoptosis. Due to the balance between pro- and anti-apoptotic signaling of TNF-R1 activation in melanoma (29), SODD may serve to tip the balance away from cell death and toward NF- $\mathrm{KB}$ activation, which is constitutively active in melanoma and important in its progression $(30,31)$. Therefore, SODD may serve a role in the anti-apoptotic functions of Bcl-2 family members $(32,33)$. Therefore, the present study detected whether BAG4 promotes the proliferation of GC cells. CCK-8 and colony formation assays indicated that overexpression of BAG4 can markedly increase the proliferation of GC cells, whereas depletion of BAG4 demonstrated the opposite results. Furthermore, overexpression of BAG4 in the AGS cell line elicited G1/G0 phase arrest and inhibited cell apoptosis, whereas depletion of BAG4 in SGC7901 cells decreased the number of cells in the G1/G0 phase and promoted cell apoptosis. This observation was confirmed in nude mice; in the BAG4 overexpressing group, the subcutaneous tumors were increased compared with the control group. These results demonstrated that BAG4 promotes GC proliferation by eliciting G1/G0 phase arrest and inhibiting cell apoptosis

In conclusion, the present study demonstrated that BAG4 promotes the invasion, metastasis and proliferation of GC cells. Further studies are required to verify the significance of BAG4, and whether it may represent a potential therapeutic target for therapies such as adjuvant chemotherapy and radiosensitization, or whether it may serve as a biomarker for the establishment of rational treatment selection criteria for patients GC.

\section{Acknowledgements}

The present study was supported by Foundation of Sichuan Health and Family Planning Commission (grant no. 150070), the Foundation of the Affiliated Hospital of Luzhou Medical college (grant no. 201567) and the National Natural Science Foundation of China (grant no. 81401927).

\section{References}

1. Siegel R, Ma J, Zou Z and Jemal A: Cancer statistics, 2014. CA Cancer J Clin 64: 9-29, 2014.

2. Cheng $J$ and Fan XM: Role of cyclooxygenase-2 in gastric cancer development and progression. World J Gastroenterol 19: 7361-7368, 2013

3. Wadhwa R, Song S, Lee JS, Yao Y, Wei Q and Ajani JA: Gastric cancer-molecular and clinical dimensions. Nat Rev Clin Oncol 10: 643-655, 2013.
4. Markar SR, Wiggins T, Ni M, Steyerberg EW, Van Lanschot JJ, Sasako M and Hanna GB: Assessment of the quality of surgery within randomised controlled trials for the treatment of gastro-oesophageal cancer: A systematic review. Lancet Oncol 16: e23-e31, 2015.

5. Briknarová K, Takayama S, Homma S, Baker K, Cabezas E, Hoyt DW, Li Z, Satterthwait AC and Ely KR: BAG4/SODD protein contains a short BAG domain. J Biol Chem 277: 31172-31178, 2002

6. Williams J, Lucas PC, Griffith KA, Choi M, Fogoros S, Hu YY and Liu JR: Expression of Bcl-xL in ovarian carcinoma is associated with chemoresistance and recurrent disease. Gynecol Oncol 96: 287-295, 2005.

7. Takayama S, Bimston DN, Matsuzawa S, Freeman BC, Aime-Sempe C, Xie Z, Morimoto RI and Reed JC: BAG-1 modulates the chaperone activity of Hsp70/Hsc70. EMBO J 16: 4887-4896, 1997.

8. Stuart JK, Myszka DG, Joss L, Mitchell RS, McDonald SM, Xie Z, Takayama S, Reed JC and Ely KR: Characterization of interactions between the anti-apoptotic protein BAG-1 and Hsc70 molecular chaperones. J Biol Chem 273: 22506-22514, 1998.

9. Wang HG, Takayama S, Rapp UR and Reed JC: Bcl-2 interacting protein, BAG-1, binds to and activates the kinase Raf-1. Proc Natl Acad Sci USA 93: 7063-7068, 1996.

10. Doong H, Price J, Kim YS, Gasbarre C, Probst J, Liotta LA, Blanchette J, Rizzo K and Kohn E: CAIR-1/BAG-3 forms an EGF-regulated ternary complex with phospholipase C-gamma and Hsp70/Hsc70. Oncogene 19: 4385-4395, 2000.

11. Doong H, Vrailas A and Kohn EC: What's in the 'BAG'?-A functional domain analysis of the BAG-family proteins. Cancer Lett 188: 25-32, 2002.

12. Cutress RI, Townsend PA, Brimmell M, Bateman AC, Hague A and Packham G: BAG-1expression and function in human cancer. Br J Cancer 87: 834-839, 2002.

13. Ozawa F, Friess H, Zimmermann A, Kleeff J and Büchler MW: Enhanced expression of Silencer of death domains (SODD/BAG-4) in pancreatic cancer. Biochem Biophys Res Commun 271: 409-413, 2000.

14. Eichholtz-Wirth H and Sagan D: IkappaB/NF-kappaB mediated cisplatin resistance in HeLa cells after low-dose g-irradiation is associated with altered SODD expression. Apoptosis 5: 255-263, 2000

15. Fletcher $\mathrm{CH}$ and Crossgrove R: Guide for the Care and Use of Laboratory Animals. Institute for Laboratory Animal Research. 8th edition. The National Acadamies Press; Washington, DC, 2011.

16. Livak KJ and Schmittgen TD: Analysis of relative gene expression data using real-time quantitative PCR and the 2(-Delta Delta C(T)) Method. Methods 25: 402-408, 2001.

17. Catalano V, Labianca R, Beretta GD, Gatta G, de Braud F and Van Cutsem E: Gastric cancer. Crit Rev Oncol Hematol 71: 127-164, 2009.

18. Takayama S, Xie Z and Reed JC: An evolutionarily conserved family of Hsp70/Hsc70 molecular chaperone regulators. J Biol Chem 274: 781-786, 1999.

19. Thress K, Song J, Morimoto RI and Kornbluth S: Reversible inhibition of Hsp70 chaperone function by Scythe and Reaper. EMBO J 20: 1033-1041, 2001.

20. Takayama S and Reed JC: Molecular chaperone targeting and regulation by BAG family proteins. Nat Cell Biol 3: E237-E241, 2001.

21. Jiang Y, Woronicz JD, Liu W and Goeddel DV: Prevention of constitutive TNF receptor 1 signaling by silencer of death domains. Science 283: 543-546, 1999.

22. Miki K and Eddy EM: Tumor necrosis factor receptor 1 is an ATPase regulated by silencer of death domain. Mol Cell Biol 22: 2536-2543, 2002.

23. Chen Y, Wang Y, Song H, Wang J, Yang H, Xia Y, Xue J, Li S, Chen $\mathrm{M}$ and $\mathrm{Lu} \mathrm{Y}$ : Expression profile of apoptosis- related genes potentially explains early recurrence after definitive chemoradiation in esophageal squamous cell carcinoma. Tumour Biol 35: 4339-4346, 2014.

24. Tao H, Hu Q, Fang J, Liu A, Liu S, Zhang L and Hu Y: Expression of SODD and P65 in ALL of children and its relationship with chemotherapeutic drugs. J Huazhong Univ Sci Technolog Med Sci 27: 326-329, 2007.

25. Takayama S, Sato T, Krajewski S, Kochel K, Irie S, Millan JA and Reed JC: Cloning and functional analysis of BAG-1: A novel Bcl-2-binding protein with anti-cell death activity. Cell 80: 279-284, 1995. 
26. Clevenger CV, Thickman K, Ngo W, Chang WP, Takayama S and Reed JC: Role of Bag-1 in thesurvival and proliferation of the cytokine-dependent lymphocyte cell lines, Ba/F3 and Nb2. Mol Endocrinol 11: 608-618, 1997.

27. Sekiya M, Adachi M, Takayama S, Reed JC and Imai K: IFN-gamma upregulates anti-apoptotic gene expression and inhibits apoptosis in IL-3-dependent hematopoietic cells. Biochem Biophys Res Commun 239: 401-406, 1997.

28. Bimston D, Song J, Winchester D, Takayama S, Reed JC and Morimoto RI: BAG-1, a negative regulator of Hsp70 chaperone activity, uncouples nucleotide hydrolysis from substrate release. EMBO J 17: 6871-6878, 1998.

29. Ivanov VN, Bhoumik A and Ronai Z: Death receptors and melanoma resistance to apoptosis. Oncogene 22: 3152-3161, 2003.

30. Madonna G, Ullman CD, Gentilcore G, Palmieri G and Ascierto PA: NF- $\kappa \mathrm{B}$ as potential target in the treatment of melanoma. J Transl Med 10: 53, 2012.
31. Poser I and Bosserhoff AK: Transcription factors involved in development and progression of malignant melanoma. Histol Histopathol 19: 173-188, 2004.

32. Reuland SN, Goldstein NB, Partyka KA, Cooper DA, Fujita M, Norris DA and Shellman YG: The combination of BH3-mimetic ABT-737 with the alkylating agent temozolomide induces strong synergistic killing of melanoma cells independent of p53. PLoS One 6: e24294, 2011.

33. Reuland SN, Goldstein NB, Partyka KA, Smith S, Luo Y, Fujita M, Gonzalez R, Lewis K, Norris DA and Shellman YG: ABT-737 synergizes with Bortezomib to kill melanoma cells. Biol Open 1: 92-100, 2012. 